\title{
Facilitating Intellectual Property Rights: A Role for Business Anthropologists
}

\author{
Alf H. Walle \\ University of Alaska, Fairbanks
}

\begin{abstract}
Mainstream intellectual property rights are granted by governments and international agreements in order to advance the goals of society. Indigenous peoples, however, often embrace their own systems of intellectual ownership that are distinct from the mainstream regime. Business anthropologists can serve both local people and mainstream corporations by facilitating a mutual understanding of the full implications of competing intellectual property regimes and doing so from a cultural as well as an economic perspective.
\end{abstract}

\section{INTRODUCTION}

Indigenous and traditional peoples not only have distinctive cultures, they often possess a rich heritage and a reservoir of intellectual property that has value for both economic and emotional reasons. Business anthropologists have a role in helping clients equitably and effectively manage these assets.

An overview of the mainstream legal regimes regarding intellectual property that have emerged in the West provides the foundation for a more nuanced and multidimensional perspective to follow. Having presented a broad background, current attempts by indigenous people and their advocates to challenge or counter the mainstream intellectual property rights regime are examined with an eye to contributions that can be made by business anthropologists.

The essay includes an analysis of international movements and collective actions that seek more appropriate systems of intellectual property treat indigenous people in a more culturally sensitive and economically equitable manner.

\section{THE WESTERN PERSPECTIVE OF INTELLECTUAL PROPERTY}

According to the mainstream perspectives of intellectual property that developed in the West and have been embraced by the developed/industrialized world, individuals (and fictive individuals, such as corporations) are eligible to earn intellectual property rights (such as patents, copyrights, etc.) if they are involved with some kind of unique discovery or creation that has a potential value to society. The goal of these laws is to channel creative activities in socially beneficial ways. Governments believe that granting intellectual property rights encourages 
people and organizations to spend money and take risks as they seek to create, discover, invent, innovate, etc. something of value to society. The potential for financial gain that results from these rights is viewed as the fuel that powers creative efforts that serve the public.

The basic elements of this mainstream regime are well known; relevant discussions related to indigenous people are readily available (Hansen and VanFleet 2003 7-35; Brascoupe and Endemann 1999 7-29, Posey and Dutfield 1996 75-92; Battiste and Henderson 2000 145-170, etc.).

According to the dominant legal regime of intellectual property rights, the "inventor" must provide full disclosure in order to gain certain protections (such as patents). These economically valuable rights, however, expire after a certain period of time. The full documentation of the intellectual property, furthermore, must be provided, making these secrets readily available to all interested parties. Discoverers, inventers, and creative individuals/organizations, in return, are granted protection for a number of years. Organizations, such as corporations, are eligible to gain intellectual property rights because in the eyes of the law they are fictive "individuals."

Those who do not act in accordance with the letter of the law, however, may lose rights they could have acquired. Consider the decision of Robert D. Ballard who discovered the location of the doomed ocean liner, the Titanic. As the person who found the lost ship, he was eligible to acquire important rights to it by virtue of his discovery. Ballard, however, wanted the ship to remain undisturbed as a sacred monument to those who lost their lives. As a result, he did not remove any artifacts.

Due to his noble gesture, Ballard did not do what was necessary to secure the rights he needed to protect the ship (extract a sample). This inaction, in turn, opened the door for others to assault the Titanic with salvage operations: exactly what Ballard wanted to avoid. Because Ballard did not act in accordance with the dominant legal structure, he lost the protection it could have provided. And when this protection is lost, others can use the knowledge he provided without restraint. Thus, the Titanic example demonstrates that if people choose not to take advantage of the options provided by the mainstream legal system, they abdicate whatever protection it might have offered.

Once legal protection expires, furthermore, the knowledge enters the public domain (and becomes the collective property of all mankind.) Giving individuals/organizations this legal protection is viewed as acting in the public interest because governments believe that this system stimulates research and creative activities that that are in the public interest. Thus, by offering short term intellectual property rights to those who create useful knowledge, the efforts of industrious individuals are channeled in a productive manner that benefits society.

Even when people no longer have a financial stake in something that they have created, however, they generally retain the right to be recognized as the discoverer, creator, or inventor. Thus, Beethoven has a right to be recognized as the composer of his music, even though he and his heirs no longer have any economic rights associated with it. These are called "moral rights," and they can be very important to people.

In general, society (governments) seeks to give people the minimum rights that are necessary to encourage the creation of new goods and services. Those who possess (or seek to possess) intellectual property rights, in contrast, typically wish to expand the scope of rights and extend the period of protection for as long as possible. Thus, some drug companies argue that they need and deserve a longer period of protection for their products because research is so costly and the industry is so risky. 
Indigenous people seeking to broaden the scope of their intellectual property rights is another example of a particular vested interest group that hopes to extend the umbrella of legal protection in ways that serve its interest. Because governments prefer to minimize the intellectual property rights that are granted, a new layer of protection will probably not be freely given.

Some critics even call for a dismantling of the intellectual property rights that do exist. Thus, Brian Martin in his Information Liberation: Challenging the Corruption of Information Power (1998) opposes the concept of intellectual property, and he even argues that laws protecting intellectual property do not work in the best interests of Third World (and by extension Fourth World) people.

Adam Smith, in his classic treatise The Wealth of Nations (1776) emphasizes that individual self-interest is an "invisible hand" encouraging worthwhile activities that promote the public welfare. Allowing creative people to acquire short term intellectual property rights in ways that serve the public interest can be viewed as an example of encouraging the invisible hand to channel efforts and resources in an appropriate manner. Smith also advocates a minimum of governmental protections and controls. Thus, according to Smith's logic, the benefits provided by intellectual property rights, while being lucrative enough to channel human efforts in productive ways, should be as minimal as possible.

As can be easily seen from the above discussion, intellectual property rights are granted to specific people (or organizations) when they create or discover something of value. Although some exceptions exist (such as trademarks and brands), intellectual property rights are usually temporary concessions that encourage research, development, and creativity that serves the public interest.

Thus, four key aspects of the dominant system of intellectual property rights are: (1) new knowledge is involved, (2) that was created by specific individuals/organizations, and (3) who divulge full information about their creation and are (4) are granted short term protection for their contribution. These aspects of the mainstream system can be presented in tabular form as Table 1.

In many ways, the mainstream regime has proven to be beneficial because it channels human effort in positive and productive ways that benefit society. Eventually, the rights expire and prices go down (as in generic drugs), which is another benefit to the public. Nevertheless, the mainstream regime was not designed to deal with the intellectual knowledge of indigenous people and enclaves of traditional culture.

As we shall see, while the mainstream intellectual property regime is dominant, many different people have their own systems that have evolved within the context of diverse cultures. Business anthropologists have a role to play in helping mainstream organizations as well as indigenous peoples to understand these differences and their implications. 
TABLE 1

THE MAINSTREAM REGIME OF INTELLECTURAL PROPERTY RIGHTS

\begin{tabular}{|c|c|}
\hline ISSUE & DISCUSSION \\
\hline Only new knowledge & $\begin{array}{l}\text { The mainstream regime of intellectual property rights focuses on new knowledge. } \\
\text { The goal of such a policy is to channel human activity in socially beneficial ways. A } \\
\text { side effect of this policy is that pre-existing knowledge is not eligible to be protected. } \\
\text { Much of the knowledge of indigenous people, however, is not "new" but } \\
\text { "traditional." As a result, the mainstream regime is not designed to protect much of } \\
\text { the intellectual property of indigenous people. }\end{array}$ \\
\hline Individual centered & $\begin{array}{l}\text { The mainstream regime of intellectual property rights centers around the individual. } \\
\text { Creative work, discoveries, etc. are copyrighted and patented in the name of the } \\
\text { individual (or fictive person) who is recognized as the discoverer, creator, inventor, } \\
\text { etc. (and submits the appropriate paperwork). Many indigenous cultures, in contrast, } \\
\text { recognize collective ownership for much intellectual property. Thus, reconciling the } \\
\text { mainstream and indigenous regimes of intellectual property can be difficult. }\end{array}$ \\
\hline Details divulged & $\begin{array}{l}\text { In order to copyright or patent materials using the mainstream regime, a full } \\
\text { description of the item must be made available (and others may see it at will). Much } \\
\text { traditional knowledge, however, does not exist in a "tangible" form. As a result, it } \\
\text { cannot be granted intellectual protection. On many occasions, outsiders have gained } \\
\text { intellectual property rights to material they borrowed because they were the first to } \\
\text { put it in tangible form and process the proper paperwork. This has been a major } \\
\text { problem. }\end{array}$ \\
\hline Time limit on protection & $\begin{array}{l}\text { The mainstream regime of intellectual property rights provides a limited period of } \\
\text { protection. The rationale for this codicil is that eventually knowledge will become the } \\
\text { collective property of all mankind, and this will cheapen products and make them } \\
\text { more readily available (as they do in the case of generic drugs). This greater } \\
\text { availability at a cheaper price is considered to be in the public's interest. The fact that } \\
\text { people cannot permanently benefit from their intellectual property, furthermore, spurs } \\
\text { continued research and development; this is also in the public's interest. }\end{array}$ \\
\hline \multicolumn{2}{|c|}{$\begin{array}{l}\text { The mainstream regime of intellectual property rights (1) deals only with new knowledge, (2) is individualistic, } \\
\text { (3) requires that all details be divulged, and (4) grants only temporary protection. As a result, this system may be } \\
\text { in conflict with indigenous visions of intellectual property rights and, for this reason, problems, tensions, and } \\
\text { misunderstandings may arise. }\end{array}$} \\
\hline
\end{tabular}

\section{THE DILEMMA OF TRADITIONAL KNOWLEDGE}

While the mainstream system works well within many contexts, it does not reflect the circumstances of many indigenous societies and the systems of ownership that they embrace. Thus, the mainstream intellectual property regime gives rights to individuals who make a discovery or invention. Indigenous societies and traditional cultures, however, often view intellectual property and heritage rights from a collective, not an individual, perspective. As a result, according to the traditions of the local community, ownership may lie with some group (such as a family, clan, or even the entire community.) This difference between the mainstream system and that of many indigenous or traditional communities demonstrates that the prevailing system of intellectual property rights is not designed with these people in mind. Such a situation can lead to the inability of the mainstream regime to serve indigenous people in equitable ways.

Certainly, to meet the letter of the law, the tribe may declare a specific person to be the "inventor" or "creator" of collectively owned intellectual property in order to patent or copyright this material. Having done so, this official "author," "discoverer," or "inventor" can assign all 
rights to the group. Such a "when in Rome, do as the Romans do" remedy, however, does not completely address the problem.

What, for example, is to prevent "rogue" individuals within an indigenous community from acting in their own best interest by inappropriately acquiring intellectual property rights for themselves for collectively owned property? Or what if a tourism company insists that a certain dance or song be performed, pointing to the fact that it is not copyrighted (and/or is public domain material) and, therefore, is the collective property of all mankind? These are issues that may need to be considered. The prevailing mainstream intellectual property rights regime is not designed to deal with such problems and conflicts.

Another issue is that only "new" knowledge is protected by the mainstream system of intellectual property rights. Much of the heritage of indigenous people has long existed within the community, and, therefore, it is not eligible for protection under the mainstream regime. Due to this technicality, the rights of indigenous and traditional people are apt to be disregarded, unrecognized, and ineligible for protection; as a result, others can use employ this knowledge at will in ways that are inequitable and offensive to the local society and its people.

From a purely practical point of view, furthermore, to gain intellectual property rights, indigenous people must wade though a mass of paperwork and legal mumbo-jumbo. Doing so, however, is complicated and may be beyond the capabilities of the people and its leaders. Once rights to intellectual property have been acquired, furthermore, the owner must work to protect these privileges and to police violations. This self-regulation involves locating evidence of counterfeiting and infringement and taking appropriate legal actions. While large and rich organizations (such as record companies) may have the resources to systematically police offenders, small local communities probably do not. In tabular form these issues can be portrayed as Table 2.

When indigenous people interact with outsiders and members of the business community, they are often advised that their intellectual property rights may be vulnerable. Due to the fact that people fear that their knowledge may not be adequately protected, they may hesitate to candidly share their traditions with outsiders. This situation might dampen the development of cooperative business ventures with the indigenous community.

Clearly, strategically minded individuals with one foot in business and the other in the qualitative social sciences are needed to help deal with these dilemmas. Thus, business anthropologists are poised to serve both corporations and cultural enclaves when issues of intellectual property arise. 
TABLE 2

PROBLEMS PRESENTED BY THE MAINSTREAM REGIME

\begin{tabular}{|l|l|}
\hline ISSUE & DISCUSSION \\
\hline Collectivity & $\begin{array}{l}\text { The mainstream regime is centered upon the individual. "Collective" knowledge is } \\
\text { not eligible for protection under the mainstream regime, but much indigenous } \\
\text { intellective property is collectively owned. This problem is sometimes resolved by } \\
\text { having a specific person pose as the "creator" and then sign all rights over to the } \\
\text { group. Many potential problems exist when using this method, however, and, it does } \\
\text { not address the true nature of many indigenous intellectual property rights regimes. }\end{array}$ \\
\hline $\begin{array}{l}\text { The mainstream regime is centered around "new" intellectual knowledge. Much of } \\
\text { the intellectual property of many indigenous people, in contrast, is traditional. As a } \\
\text { result, this heritage is not eligible for protection under the mainstream intellectual } \\
\text { property regime. }\end{array}$ \\
\hline $\begin{array}{l}\text { Phile indigenous peoples (especially rural enclaves) may possess intellectual } \\
\text { property that is eligible for protection, they might not have the money and technical } \\
\text { expertise required to process applications, etc. As a result, these groups are } \\
\text { disenfranchised from mainstream intellectual property rights protection. }\end{array}$ \\
\hline $\begin{array}{l}\text { Enforcement problems } \\
\text { Even when protection to intellectual property has been granted, the people possessing } \\
\text { these rights must police the fair use of their property. Large Western firms, such as } \\
\text { music companies, are able to do this. Many small indigenous communities, in } \\
\text { contrast, are typically not in a position to do so. As a result, even if they are granted } \\
\text { intellectual property rights, pirates may continue to violate them without punishment. }\end{array}$ \\
\hline $\begin{array}{l}\text { Indigenous people are beset with a wide array of problems concerning their intellectual property. The mainstream } \\
\text { method does not adequately deal with collective ownership and only protects "new" (not traditional) knowledge. } \\
\text { Even when small ethnic enclaves have a right to gain intellectual property protection, a lack of money and } \\
\text { technical expertise often stifles their efforts. And once rights have been acquired, the owner must protect its } \\
\text { interests; while a large firm } \\
\text { indigenous commun be able to do so, small communities typically do not have the resources to police }\end{array}$ \\
\hline
\end{tabular}

\section{THE CASE OF FOLKLORE}

Many outsiders, including members of the business community, hope to learn about the people they visit. Because (1) the origins tend to be shrouded in the past, (2) no specific creator can be identified, and (3) the knowledge does not exist in tangible form folklore tends to be viewed as public domain knowledge that cannot be protected by intellectual property rights. These loopholes create a situation where the only way that people can protect their intellectual knowledge and heritage is not to divulge it in the first place (a situation that militates against cultural sharing in ways that otherwise could benefit all interested stakeholders).

In recent decades, however, there has been a growing recognition that the folkloristic heritage of people should be protected. A pioneering effort is the Tunisian Literary and Artistic Property Act which states that artistic works inspired by the folklore and cultural heritage of Tunisia cannot be copyrighted without permission of the Tunisian government. In 1971 the Berne Convention (international agreement on international property), was amended so governments could assign "component authorities" to control the use, licensing, etc. of folklore. In 1976, the Tunisian model law for the protection of folklore was drafted. In 1997, UNESCO and the World Intellectual Property Organization sponsored a forum in Thailand regarding the protection of folklore. (For details on these and other efforts to extend intellectual property rights to folklore, see Battiste and Henderson 2000 210-3.) 
The issue is this: "folklore" is knowledge that is handed down orally. As a result, it is intangible cultural expression. To gain intellectual rights according to the mainstream intellectual property regime, however, something has to exist in a tangible form. This issue has often resulted in outsiders gaining intellectual property rights to materials they didn't create because they were the first to put it in a tangible form (by writing it down, recording it, etc.). On other occasions, artists (such as singers) have been able to record folksongs that are in the public domain, copyright their renditions of this lore, and earn generous royalties while giving the true creators nothing. This situation is inequitable, and efforts are underway to correct this imbalance. At the present time, however, a workable solution has not been developed.

As a result of this situation, many cultural enclaves and indigenous people are unwilling to cooperate with outsiders in economic development projects that utilize their intellectual property. As a result, all lose. Business anthropologists with knowledge of business coupled with ethnographic insights are in a position to help forge policies and strategies that are acceptable to all impacted individuals, groups, and organizations.

\section{THE INDIGENOUS PERSPECTIVE}

Discussing indigenous knowledge is a very difficult task because specific people are distinctive and unique. Hundreds and thousands of unique indigenous societies exist, so talking about them in general terms is impossible. Nevertheless, many different peoples are banding together for their mutual benefit. By collectively addressing issues concerned with intellectual property rights, more effective strategies for enhancing their rights can be advanced.

A useful way to envision the knowledge of indigenous people is to emphasize the role that tradition often plays. Hansen and Van Fleet observe (2003 3), paraphrasing the World Intellectual Property Organization:

The term traditional used in describing this knowledge does not imply that this knowledge is old or that it is not technical, but...."traditionally based." It is "traditional because it is created in a manner that reflects the traditions of the communities, therefore not relating to the nature of the knowledge itself, but to the way in which that knowledge is created, preserved, and disseminated.

This perspective is useful because although a specific indigenous culture is unique, many different groups may have similar or parallel ways of gathering, owning, and maintaining their heritage and intellectual property. Mari Olson (a Tlingit elder and a professor of intellectual property rights for the University of Alaska at Fairbanks) observes that the Tlingit people own intellectual property collectively (through a family, clan, community, etc.). Thus, their system of intellectual property rights is very different from that of the dominant mainstream regime that emphasizes the individual. These alternative systems of ownership tend to be (1) distinct from, (2) sometimes in conflict with, and (3) typically ignored by the larger mainstream society and its legal structure.

In some instances, indigenous people seek to affirm rights that the existing mainstream legal code does not acknowledge. Thus, the Hopi Tribal Council Resolution H-70-94 states (quoted in Downey 1998 3): 
Be it further resolved by the Hopi Tribal Council that archival records, including field notes, audio tapes, video tapes, photographs; which describe and depict esoteric rituals, ceremonial and religious knowledge, be placed under restriction by museums and other repositories for public access and hereby declared to be the cultural property of the Hopi people.

In a hypothetical example, a particular indigenous individual may know a certain song that is well documented in books and, therefore, it is in the public domain (according to the mainstream regime of intellectual property rights). In the eyes of the community, however, that song may be the perpetual property of a certain clan or family. As a result, it cannot be legally performed according to tribal traditional law unless the collective owner(s) gives permission. Thus, the indigenous system would not recognize that the intellectual knowledge had entered the public domain.

If a music company does not understand that the song is owned by a particular group, it might reason that it is in the public domain and seek to make a recording. Doing so, however, would not be appropriate according to the indigenous intellectual property regime. Intellectual property stemming from the indigenous community may need to be envisioned in terms of the local protocols of ownership and its traditions of ownership, not merely with reference to the mainstream intellectual property rights regime. Business anthropologists have a role in dealing with such confusion.

\section{CONTEMPORARY ACTIONS}

Increasingly, a variety of indigenous peoples are thinking in terms of collective action in order to protect and enhance their heritage and intellectual property rights. People as diverse as the Maori of New Zealand, Native Hawaiians, and Native Alaskans are working together for their collective benefit. By joining forces these peoples are dealing with issues that were previously inadequately addressed. This more collective response may be giving people the critical mass that they need to challenge the mainstream regimes of intellectual property rights.

The goal of this collaboration is to work in a synergistic and mutually beneficial manner to strengthen the indigenous heritage and intellectual property rights. The emerging strategy involves creating a unified challenge to aspects of the mainstream regime that undercut traditional intellectual property traditions.

Various initiatives exist to strengthen and transform intellectual property and heritage rights so they more appropriately reflect the perspectives and needs of indigenous people. Particular examples include:

1. Working within the context of the mainstream legal system.

2. Changing the mainstream legal framework

3. Working within the framework of indigenous legal traditions

4. Seeking new legal frameworks.

5. Seeking and developing extralegal methods

6. Practicing secrecy

7. Affirming moral rights

Each will be briefly discussed. 


\section{Working within the Context of the Mainstream Legal System}

Although the mainstream legal system may be alien, many indigenous people feel they have no option except to rely upon it. While some may balk at doing so and refuse to adhere to what they feel are foreign legal regimes, others are willing to utilize whatever legal remedies are at their disposal even if doing so violates traditional codes of ownership. Sadly, many people are unaware of how the dominant legal structure works, and they have no advocates who can help them understand the dominant legal framework and how to use it to their advantage. Business anthropologists may be able to serve in this role.

Internationally, efforts are being exerted to make indigenous people more aware of their intellectual property rights within the context of the mainstream legal system. An outstanding example of this trend is Stephen A. Hansen and Justin V. VanFleet's Traditional Knowledge and Intellectual Property: A Handbook on Issues and Options for Traditional Knowledge Holders in Protecting Their Intellectual Property and Maintaining Biological Diversity. (2003). That book reviews the legal framework of the mainstream culture and presents it in everyday language. The goal of the authors is to provide average people with advice that can be understood without the assistance of a lawyer or mainstream expert. Besides being a primer on intellectual property law, the authors provide a number of worksheets that readers can use to formulate their own conclusions regarding how to proceed in regard to their heritage and intellectual property.

In addition, a number of lawyers and legal aid organizations are happy to help indigenous people in matters concerning intellectual property and heritage rights. One such organization that is located within the United States is the Native American Rights Fund, located in Boulder, Colorado. The organization has a useful website (www.narf.org) that provides a wealth of useful information. The National Indian Law Library is associated with the Native American Rights Fund and can be accessed at the NARF website presented above.

These sample resources are meant to be illustrative, not exhaustive. A wide array of advice is increasingly available that can help indigenous people to protect their intellectual and heritage rights.

\section{Changing the Mainstream Legal Framework}

While some indigenous and traditional people are adapting themselves to the mainstream legal framework, efforts are also being made to transform the mainstream legal framework in appropriate ways. Sometimes these changes are small and subtle, but on other occasions, they can be dramatic. One particularly far-reaching bit of legislation is the Native American Grave Protection and Repatriation Act of 1990 of the United States. This law provides protection for human remains, artifacts associated with human remains and funerals, as well as other sacred objects. The goal of the law is to give Native American communities greater control over their heritage. As a result, museums are required to create an inventory of these materials and work with appropriate Native groups in order to adhere to their desires. Although this law does not cover all artifacts (such as those in private collections gathered before a certain date), the law is an excellent example of how a changing mainstream legal structure is helping indigenous peoples to achieve greater control over their heritage.

Some observers, such as Claire Farrer (1994) feel that the rights granted by the Native American Graves and Repatriation Act can and should be extended beyond physical objects to include stories, sacred tales, and the like. While Farrer refers to a specific law in one country and proposes expanding its application, her thinking demonstrates a trend towards granting greater heritage rights to indigenous people. It is equally important to note that these rights would accrue 
to the group, not to individuals as in the mainstream intellectual property rights regime. While the United Nations has not formally advocated acknowledging the collective ownership of intellectual property, there seems to be a trend in this direction.

It needs to be noted, however, that the various declarations that have been signed and published often take the form of a "wish list" that has no legal force. The framers of these codes are firing the first salvos in a long-term process of negotiation. In Hegelian fashion, the prevailing "thesis" (existing law) is opposed by equally one-sided rebuttals. Ultimately and in the long term, some compromise will probably be reached. Currently, however, this "synthesis" has yet to be worked out.

In his Sacred Objects and Sacred Places: Preserving Tribal Traditions (2000) Andrew Gulliford provides a detailed discussion of both the repatriation of objects to their appropriate cultures and other topics such as the use of sacred sites, an issue that might have implications involving cultural and intellectual property This movement, furthermore, is international in scope. The reader is directed to the work of Terri Janke, $(1999,2003)$, a lawyer of Australian Aborigine descent who has written widely on indigenous and indigenous people and intellectual property rights. Resources such as these further emphasize the efforts that are being made to transform the legal structure in ways that mesh more appropriately with indigenous perspectives of ownership that are independent of the Western tradition and the developed, industrialized world.

\section{Working within the Framework of Indigenous Legal Traditions}

In many cases, the legal rights of indigenous peoples are being defended with reference to their own pre-existing legal framework. Third and Fourth World people often have the status of a semi-sovereign "nation within a nation." In the United States, as a specific example, the indigenous legal framework tends to remain in full force except where specific parts of it have been extinguished by the federal government through an act of Congress. The term used to identify these rights is "un-extinguished powers."

According to Judge Jim Bowen, a lawyer and Judge who often functions as a Judge Pro Temp (ad hoc judge for a particular case) in Native American courts, these "un-extinguished powers" can sometimes be used to affirm and defend cultural property and heritage rights (Personal Communication 2005.) Bowen was the judge in an important Native court case involving some priceless artifacts that a Native community insisted had been stolen from the community. In this case, "Chilkat Indian Village vs. Johnson et al" (Indian Law Review 1993), the defendants justified their actions by pointing out that according to the mainstream legal system they were the owners of this artwork and, therefore, they could dispose of the items in any way they saw fit.

The community, in contrast, justified its position with reference to a ruling it had made regarding artifacts that affirmed that they could not be removed from their location without permission (which, in this case, was never given). This ruling was made in accordance with traditional law, based on oral traditions. The argument presented by the community was clearly hinged on the premise that the legal system of a local Alaska Native (indigenous) community can override state and national statutes in a case involving the intellectual traditions and heritage of the people.

The verdict was in favor of the community. The legal traditions of the local indigenous group prevailed and the artifacts were returned to the community. This decision reinforces the principle that tribal law (even if not written down and existing only in tradition) is binding. Alaska Native 
(indigenous) communities do not need a written constitution. The source of authority is the "unextinguished power" that has not been explicitly taken away by the federal government. Bowen emphasized that unless Congress has explicitly extinguished a power, it remains in full force.

No appeal was ever made by the defendants so the ruling never entered the United States Court system (the case was handled entirely in Native courts). Bowen noted that because the case was not appealed (and did not re-enter the United States Court system) it did not emerge as precedent setting in the United States' legal system. Nevertheless, it was a victory for Native property rights and it indicates that indigenous legal traditions can be used to defend Native and indigenous rights.

In many parts of the world, indigenous peoples have rights that are analogous to the "unextinguished powers" that are possessed by Native Americans in the United States. As indigenous legal traditions are revitalized, they may begin to impact intellectual property rights. A business, for example, might depend upon certain elements of indigenous culture that, it asserts, are in the public domain. If the "unextinguished powers" perspective prevails, the community may regain the rights to control and regulate these cultural traditions. This could have an impact upon businesses that make use of the indigenous heritage. Business anthropologists might be of service in such situations.

\section{Seeking New Legal Frameworks}

Currently, indigenous peoples are struggling to enhance their legal rights. In many cases, this is a first step in seeking equity and parity. A legal underpinning of this trend is the reaction of the world community to the Nazi atrocities of World War II. Previously, the legal system assumed that nations had unlimited rights within their territories. The events of the war, however, gave rise to the belief that people possess certain inherent rights that may not be abridged or violated, even by a sovereign nation. According to Wiessner (1999), "The United Nations Charter put human rights and self-determinism of peoples first, making them a raison d'etre of the new worldwide organization of governments."

Currently, various indigenous groups are seeking to create a broader legal framework in order to better protect their rights. The process of doing so often entails rethinking what should be protected by intellectual property rights (especially the view that being able to benefit from one's heritage and intellectual property is an inalienable right).

The evolving way in which folklore is envisioned appears to be at the heart of the issue. As discussed above, folklore is knowledge that is passed on by word of mouth and by personal example without ever being written down or put in any tangible form. According to the mainstream intellectual property regime, knowledge that is intangible cannot be protected. This situation creates a profound problem for peoples whose traditions are transmitted and preserved orally because the mainstream legal system is not set up to protect their rights. This inability has caused considerable concern.

An example of the problems associated with the existing legal framework has been presented by Tony Seeger (1991). He laments that individuals who give performances closely based on indigenous traditions can gain intellectual property rights for their efforts, while the people who invented the tradition receive nothing, because the material was not written down and copyrighted and/or because it is viewed as part of the public domain. Thus, a singer can record a "traditional song" without the payment of royalties to the culture that created it. Seeger is aware of the complex issues involved in this situation, and he clearly understands that the laws need to 
be changed to equitably deal with indigenous people. He is also aware of the difficulty in doing so.

The United Nations and other groups such as the World International Property Organization, the Organization of American States, etc. have provided an array of initiatives designed to extend the legal rights of indigenous people. On many occasions, these efforts result in some kind of declaration that is not legal, but aspires to influence future national and international laws/procedures, protocols, etc. Although these documents are not laws, they are intended to influence future legislation both nationally and internationally.

\section{Seeking and Developing Extralegal Methods}

In the meantime, these actions and recommendations can serve as an extra-legal means of encouraging people, organizations, and nations to act in certain ways. Various voluntary agreements (such as letters of intent, memoranda of understanding, and statements of professional ethics) have been drawn up. While the official protection of such methods is weak, they can still help people to protect their heritage and intellectual property rights. (See Posey and Dutfield 1996 68-74).

Consider, for example, Tony Seeger's "Plan of Action" regarding a people's musical heritage. Seeger suggests combining legal and extra- legal remedies in ways that include:

1. New conventions must respect local traditions of music ownership...

2. Any new conventions must be more than a set of laws [without teeth.] We need effective ways of ensuring that payments can be made and will reach the appropriate parties...

3. [To avoid others unjustly profiting, rights should be assigned]... at a local level rather than as "national patrimony to be absorbed by the state."

4. Musicians, researchers, and record producers all need to be more aware of the rights and sensitivities of the peoples whose music they adapt, research, and produce

5. The general public, as always, can prod individuals and companies to act more responsible... (Seeger 1991 38.)

While Seeger's plan of action is concerned with music, many of his suggestions apply to other areas of intellectual property, as well. His work can be used as a model for an example of ways to protect the intellectual property and heritage rights of host communities.

An organization, for example, that chooses to ignore the suggestions provided by such documents may receive censure from a coalition of indigenous communities as well as those who support them. This can lead to bad publicity that further undercuts the organizations. This pressure (or the threat of it) may force organizations to adjust their behavior even if they do not have a legal obligation to do so. By having a plan of action such as this, indigenous people may be able to use the resulting leverage to protect their rights via extra-legal means.

\section{Practicing Secrecy}

An age-old remedy for protecting heritage and intellectual property rights is to practice secrecy. Companies, such as Coca-Cola, never patent their formulas and recipes because by doing so the organization would have to reveal its secrets and the intellectual property rights might eventually expire. As a result, the organization keeps the recipe secret and, thereby, it maintains the exclusive rights to this intellectual property on a permanent basis. Many indigenous people employ this method. It is the only way to totally and permanently protect 
certain sensitive knowledge. As a result, knowledge is often withheld from certain people. James Nageak (personal communication 2005), for example, recalled that during a trip to visit the Hopi an opportunity presented itself to see Cachina dolls that have a religious significance. Nonindigenous people were not allowed to participate in this activity, although he was allowed to go because he is a Native, even though not a Hopi.

Nageak also discussed the situation where a community college offered a course on how to make traditional baleen baskets (a traditional craft of the Alaska Native community). When the time for instruction arrived, two Alaska Native students showed up. Ten other class members were white. The instructor, a Native man, refused to teach the whites. This was his way of using secrecy to protect the intellectual property rights of his culture. In view of the fact that baleen baskets often sell for hundreds of dollars, he was protecting traditional knowledge that has both cultural and economic significance.

Secrecy is an age old remedy for protecting a people's heritage and intellectual property rights. On many occasions, the strategy is more effective and appropriate than formal legal means. If a host community resorts to secrecy, however, this decision may have a negative impact upon needed and wanted economic contact with the outside world. To prevent such unwanted side effects, outside organizations and host communities may need to work together for their mutual benefit while protecting the local community as required.

\section{Affirming Moral Rights}

As indicated above, even when people lose an economic interest in their work, they typically still retain the right to be recognized. In the example given above, even though Beethoven and his descendents have no financial stake in the music he created, he still has the right to be recognized as the composer.

Even when indigenous people no longer have financial rights to their creations or traditions because they have passed into the public domain, etc., increasingly there is a demand that their contributions be recognized. I have heard indigenous people complain, for example, that various "new age" gurus employ indigenous traditions, take them out of context, and wrongly assert that they are intimately connected to shamans, etc.

Many indigenous peoples resent charlatans co-opting their heritage. Designers, furthermore, routinely borrow the designs of specific indigenous people but merely depict them as "tribal" or "folk inspired" and provide no indication of the unique culture that created the style.

On many occasions, promotional strategies that make sense from a marketing perspective appear as hurtful when the host community and its members are considered. People who are buying crafts, for example, want to meet the artist. Bona fide traditional craftspeople, however, are in short supply, and they often function poorly or are uncomfortable with large groups of mainstream people. As a result, some clever marketers have hired others (who may merely be actors) to pose as craftspeople, answer questions, and fulfill the demands of tourists who want to "meet the artist." Although the people using such tactics do not view themselves as "plagiarists" this misrepresentation can be very hurtful to the actual craftsperson. A few years ago I was attending a meeting on folk art presented by the National Endowment of the Arts. A basket maker in attendance recalled how others had been hired posed as the artist how had done her work. She observed "It hurts when somebody else puts their name on your baskets."

It is clear that even though the marketer might have bought the baskets and owned them, this craftsperson was denied her moral rights. Increasingly objections to this type of treatment are being made in a forceful manner. These methods are abstracted in the Table 3. 
TABLE 3

\section{USEFUL METHODS}

\begin{tabular}{|l|l|}
\hline ISSUE & DISCUSSION \\
\hline Use mainstream regime & $\begin{array}{l}\text { Due to the power of the mainstream regime, many indigenous people choose work } \\
\text { with it in order to protect their intellectual property rights. }\end{array}$ \\
\hline $\begin{array}{l}\text { Change mainstream } \\
\text { regime }\end{array}$ & $\begin{array}{l}\text { It might be possible to work within the framework of the mainstream regime to } \\
\text { make it more responsive to the needs of indigenous people. }\end{array}$ \\
\hline Use indigenous regime & $\begin{array}{l}\text { Indigenous people have their own intellectual property regimes. It might be } \\
\text { possible to reaffirm and bolster these traditions in order to expand the degree to } \\
\text { which indigenous intellectual property is protected. }\end{array}$ \\
\hline Seek new legal framework & $\begin{array}{l}\text { Various groups are attempting to establish new legal frameworks for intellectual } \\
\text { property. They may provide future protection. }\end{array}$ \\
\hline Extra legal methods & $\begin{array}{l}\text { Extra legal methods, such as agreements, policies, and pressure on organizations } \\
\text { may be able to extend intellectual property rights. }\end{array}$ \\
\hline Secrecy & $\begin{array}{l}\text { When maintaining protection is very important, secrecy can always be used. Doing } \\
\text { so, however, will inhibit the benefits that could come from sharing and no } \\
\text { protection from the mainstream regime will be acquired. }\end{array}$ \\
\hline \multicolumn{2}{|l|}{$\begin{array}{l}\text { Moral rights involve the right to recognition for achievements even when economic } \\
\text { rights do not exist or when knowledge has entered the public domain. Nonetheless, } \\
\text { these moral rights have significant value to people and cultures. }\end{array}$} \\
\hline $\begin{array}{l}\text { Indigenous peoples have a wide array of tools and methods that can be used to protect and enhance their } \\
\text { intellectual property rights. This, furthermore, is an area this is rapidly changing. As a result, benefits that do not } \\
\text { yet exist might become available in the future. }\end{array}$ \\
\hline
\end{tabular}

\section{Analytic Statement}

Indigenous people have a number of techniques at their disposal that are designed to protect their heritage and intellectual property rights. Currently much work is taking place in this regard, and new developments in this area can be expected. In general, progress is being made, but more needs to be accomplished. The discussions above are illustrative of a trend, and they are not meant to be exhaustive. They demonstrate a number of ways in which indigenous people are reaffirming their heritage and intellectual property rights.

Business anthropologists with their dual knowledge of indigenous peoples and business methods can serve as a conduit providing insights to both corporate leaders and cultural enclaves.

\section{DISCUSSION AND CONCLUSION}

Mainstream views of intellectual property rights center on the individual (or a surrogate individual, such as a corporation). Traditional people, in contrast, often think in terms of the social group as a collective entity. In their legal traditions, ownership may reside with some group, not a specific individual. These are basic conflicts that need to be discussed and clarified in order for the traditions of ownership embraced by indigenous cultures to better mesh with the global system that has evolved.

Protecting the cultural heritage and intellectual property rights of people has both economic significance and can lead to the emotional well-being of the community. As a result, the issue is complex and multi-faceted. Indigenous people need to envision this situation in all its complexity. Those who seek to use their traditions and cultural heritage for ad hoc business and profit making ventures need to be aware of the complexities involved in doing so. 
Since the Western/industrialized system assigns intellectual property rights in order to encourage the creation of new products and services, providing protection to knowledge that has long existed goes against the grain of dominant legal precedents. As a result, moving in this direction may be difficult. Because much of the heritage and intellectual property of indigenous people is folklore that has long existed, protecting it legally can be difficult.

Nonetheless, various tactics are being used in order to strengthen the rights of indigenous people. As this movement gains clout, the resulting transformations may begin to exert an influence over the way outsiders interact with indigenous people. Businesses that deal with indigenous people need to be aware of this trend. Host communities and their advocates, in contrast, should be aware of the fact that new tools that are designed to protect a wide array of intellectual traditions may be on the horizon.

Thus far in its short history, business anthropology has been largely viewed as an exotic research method that provides qualitative information to decision makers. Business anthropologists, however, have the potential to serve as strategists and decision makers because their expertise (1) transcends while embracing business methods, (2) is enhanced by the insights of the social sciences, and (3) typically embraces an understanding of indigenous and traditional peoples.

In the field of intellectual property, for example, business anthropologists have a rich tool kit of value in both analyzing situations and proposing viable strategies. As a result of this special knowledge and skill, business anthropologists are poised to assume a leadership role when questions of intellectual property arise.

By exercising their diverse blending of business/economic and social/cultural skills, business anthropologists can potentially help both mainstream corporations and cultural enclaves achieve their respective goals in a "win-win" environment.

\section{RELEVANT TERMS}

Author: The author is the person who is recognized as the creator of a work. In mainstream intellectual property law this tends to be an individual. According to indigenous traditions, however, the author may be a collective entity.

Community Controlled Research: The local community (after being made aware of the research and its implications) approves. The research may be conducted by the community or by others. In many cases, collaboration will occur.

Copyright: Copyright is a form of protection provided to the authors of "original works of authorship" including literary, dramatic, musical, artistic, and certain other intellectual works, both published and unpublished.

Counterfeit: A product that purports to be authentic, but in fact is not. Many replicas of indigenous crafts which are sold as authentic are counterfeit.

Cultural Context: Human attitudes, beliefs, and knowledge, etc. needs to be viewed from within the social and cultural context in which it exists (or existed.) If these perspectives are not provided, misconceptions can occur. They are to be avoided. 
Cultural Heritage: The collective traditions, beliefs, etc that a people possess that has been handed down or created by them.

Culturally Sensitive Information: Some information may be sacred, secret, or cause damage if it is publicly known. Special care must be taken with this information. Those who share culturally sensitive information need to alert those who are gathering it regarding the sensitive nature. Those giving this information need to protect that information by gaining a signed form stating the information will not be used in inappropriate ways. The directives need to be very specific.

Culture: Patterns of clusters of learned behavior that fit together. Different people have distinct cultures and cultural traditions. These cultures serve various roles. Since all aspects of a culture tend to be interconnected, if one component of culture or its environment is changed, other components are likely to be transformed.

Customary Law: Rules that have existed so long that they are accepted as law and international law. Many indigenous people feel that their traditions of ownership should be recognized as customary law.

Folklore: Traditional knowledge that is part of an oral tradition and not written down. Because it does not exist in a tangible form, it does not meet the usual requirements of copyrightable material. Indigenous people tend to disagree.

Heritage Rights: Certain rights people have to their traditions. Examples may be the right to worship in a traditional sacred place, the right to the bones of one's ancestors, etc.

Inalienable: Whatever cannot be denied a person. Indigenous communities often feel that certain things that individuals can typically sell are actually inalienable. (The rights for a people to own certain intellectual traditions, for example, are inalienable in the eyes of many people, but this may conflict with mainstream law.)

Infringement: Unauthorized use of intellectual property protection.

Intellectual Property: Under specific circumstances, governments give individuals rights to the products of their creativity, research, discovery, etc. These are known as intellectual property rights.

Moral Rights: Authors often retain the right to recognition of their accomplishments even if the information itself is in the public domain. Thus, artists continue to be recognized as creators even after their economic rights in their work have expired. Indigenous people should be honored by having their moral rights recognized if, for example, a mainstream author is inspired by the legends, etc. of a specific indigenous people.

Not Patentable: It has been held that the laws of nature, physical phenomena, and abstract ideas are not patentable. 
Patent: Intellectual property rights granted to an inventor, discoverer, creative force, etc. issued for a period of years. After patent expires the item becomes part of the public domain.

Public Domain: Knowledge that is not protected by intellectual property rights is in the public domain. Anybody can use this material without any limitations. Knowledge in the public domain is considered to be part of the collective knowledge of mankind. Indigenous people are often concerned because mainstream intellectual property rights often treat the knowledge of indigenous people as public domain information, while indigenous disagree.

Royalty: A payment (typically a stated percentage) for units sold that is based on materials that are owned by others.

Trademark: A trademark is a word, name, symbol, or device that is used in trade to indicate the source of the goods and to distinguish them from the goods of others. The terms "trademark" and "mark" are commonly used to refer to both trademarks and service marks.

Useful: The patent law specifies that to be protected intellectual property must be "useful." The term "useful" in this connection refers to the condition that the subject matter has a useful purpose and also includes operativeness, that is, a machine which will not operate to perform the intended purpose would not be called useful, and therefore would not be granted a patent.

\section{ENDNOTE}

My first introduction to intellectual property rights and indigenous people was given to me by Professor Marie Olson who taught a graduate seminar entitled "Cultural and Intellectual Property" for the University of Alaska. I am grateful to Olson and to the other students in the course. While acknowledging Olson's leadership and the contributions and insights of other students, I am responsible for any errors that the readier might find.

\section{REFERENCES}

Battiste, Marie and James Sa'ke'j Henderson (2000) Protecting indigenous Knowledge and Heritage, Saskatoon: Purich Publishing.

Brascoupe, Simon and Karin Endemann (1999) "Intellectual Property and Aboriginal People" A Working Paper", Ottawa: Minister of Indian Affairs and Northern Development.

Downey, Laura (1998) A Tourist Album and its Implications for the Intellectual Property Rights of indigenous Peoples WAAC Newsletter May 1-8 pagination refers to web version.

Gulliford, Andrew (2000) Sacred Objects and Sacred Places: Preserving Tribal Traditions, Boulder, Colorado: University of Colorado Press.

Hansen, Stephen A and Justin V. VanFleet (2003) Traditional Knowledge and Intellectual Property: A Handbook on Issues and Options for Traditional Knowledge Holders in Protecting 
Their Intellectual Property and Maintaining Biological Diversity. New York: American Academy for the Advancement of Science.

Janke, Terri (2003) Minding Culture: Case Studies on Intellectual Property and Traditional Cultural Expression, Geneva: World Intellectual Property Organization.

Janke, Terri (1999) Our Culture: Our Future: A Report on Australian indigenous Cultural and Intellectual Property Rights, Australian Institute of Aboriginal and Torres Island Studies.

Jones, Patrice (2002) Brazilian Tribe Feels Betrayed by Plant Search", Seattle Times September 16.) Retrieved in October 2010 at the Seattle Times website

$\mathrm{http}: / /$ seattletimes.nwsource.com/html/home/index.html .

Martin, Brian (1998 Information Liberation: Challenging the Corruption of Information Power, London: Freedom Press.

Olson, Marie (2005) Personal communication. February.

Posey, Darrell A. and Graham Dutfield (1996) Beyond Intellectual Property: Toward Traditional Resource Rights for indigenous Peoples and Local Communities, Ottawa: International Development Research Center.

Seeger, Anthony (1991) "Singing Other People's Songs" Cultural Survival Volume 16 (summer) pp 36-9.

Smith, Adam (1776) The Wealth of Nations

Wiessner, Siegfried (1999) "Rights and Status of indigenous Peoples: A Global and Comparative and International Legal Analysis" Harvard Human Rights Journal, Vol. 12: 57-128. 